\title{
Gemeinsam Bildung gestalten
}

$5 / 2017$

\section{//// BLGS}

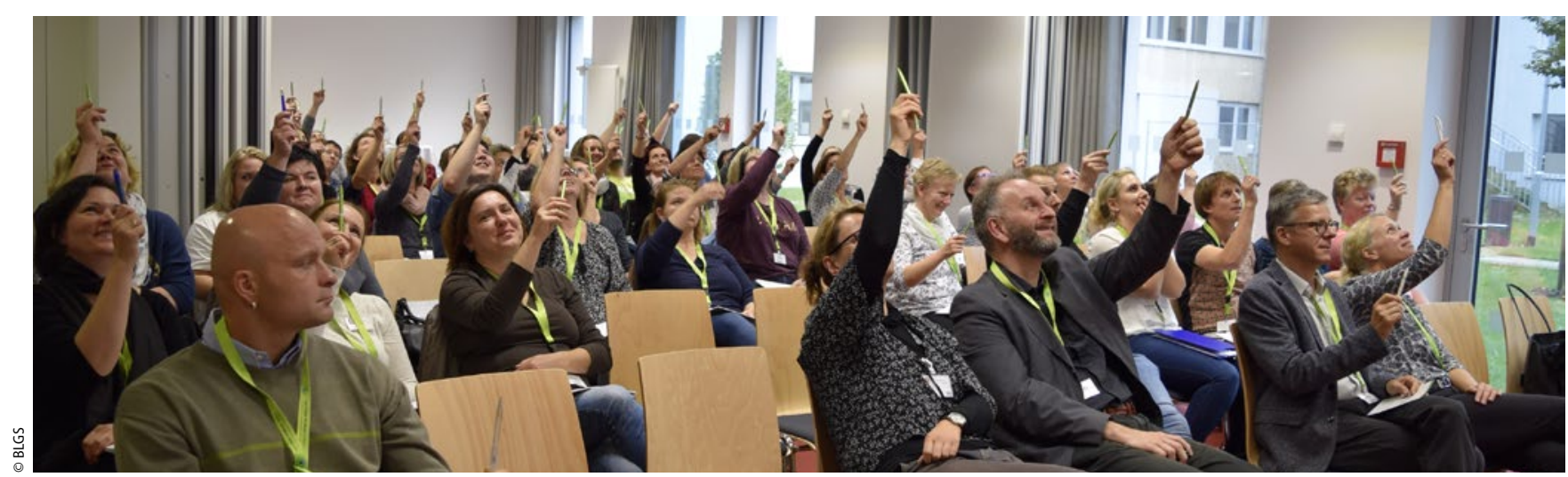

Aufbruchstimmung im BLGS-Landesverband Brandenburg: Die AG Praxis will hoch hinaus!

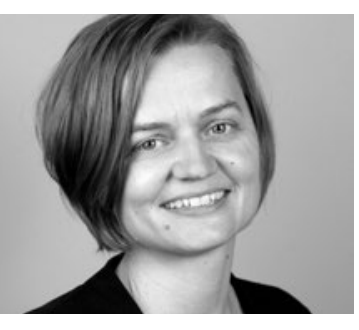

Liebe Kolleginnen und Kollegen,

das Jahr 2017 ist schon fast wieder vorüber und mit dem November endet auch die Saison der Herbsttagungen in den Landesverbänden, über die wir in dieser Ausgabe berichten. Hier hat sich das Pflegeberufereformgesetz als Dauerbrenner etabliert - im Frühjahr soll nun endlich die lang erwartete Ausbildungs- und Prüfungsver-

\begin{abstract}
"Bester Pflegelehrer Deutschlands 2017"
Anlässlich einer Festveranstaltung zum Tag des Pflegelehrers, die am 06. Oktober 2017 in Bochum stattfand, wurde Dr. Andreas Bock, Leiter des Bildungszentrums Niederrhein Wesel und Mitglied im BLGS, als Bester Pflegelehrer Deutschlands 2017 geehrt. Der in diesem Jahr erstmals ausgelobte Siegfried-Huhn-Ehrenpreis des Deutschen Vereins zur Förderung pflegerischer Qualität e.V. wurde von dessen Präsidenten, Jens Frieß, überreicht. Zur Besten Praxisanleiterin Deutschlands 2017 wurde Wencke Seuberling von der Pro Seniore Residenz Noris Nürnberg gekürt.
\end{abstract}

Wir gratulieren! ordnung vorgelegt werden und wir sind gespannt, was sie uns bringen wird.

Derweil wird unter der Regie der Landespflegekammer in Rheinland-Pfalz intensiv an der Entwicklung der Weiterbildungsordnung gearbeitet. Zum ersten Mal in der Geschichte obliegt es damit einer berufsständischen Vertretung von Pflegenden in Deutschland, selbst die Gesamtverantwortung für einen wesentlichen Teil der pflegeberuflichen Bildung zu übernehmen. In diesen Prozess ist auch der BLGS als DPR-Mitgliedsverband im Rahmen einer gemeinsamen Stellungnahme involviert. Besonders spannend wird aus unserer Perspektive die Gestaltung der Weiterbildungsordnung für Praxisanleiterinnen sein, über die wir bei Gelegenheit noch ausführlicher informieren werden.

Mehr öffentliche Aufmerksamkeit erfahren zukünftig auch hervorragende pflegepädagogische Leistungen: 2017 wurden erstmals der "Beste Pflegelehrer" und die "Beste Praxisanleiterin" gekürt; ab 2018 wird der BLGS-Landesverband NRW einen Nachwuchspreis für berufspädagogische Abschlussarbeiten vergeben.

Wir wünschen viel Spaß beim Lesen und eine besinnliche Vorweihnachtszeit!

Herzlich thre

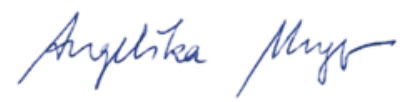

BLGS-Newsletter-Redaktion 